\title{
RAPID ENRICHMENT OF PEPTIDES WITH CALCIUM-CHELATING CAPACITY AND CHARACTERIZATION OF PHYSICAL CHEMICAL PROPERTIES
}

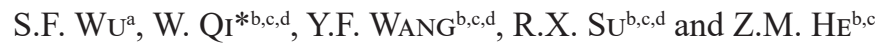 \\ ${ }^{\mathrm{a}}$ College of Food Science and Engineering, Tianjin University of Science and Technology, Tianjin 300457.People's \\ Republic of China \\ ${ }^{\mathrm{b}}$ State Key Laboratory of Chemical Engineering, School of Chemical Engineering and Technology, Tianjin \\ University, Tianjin 300072. People's Republic of China \\ ${ }^{c}$ Collaborative Innovation Center of Chemical Science and Engineering (Tianjin), Tianjin 300072. People's \\ Republic of China \\ ${ }^{\mathrm{d}}$ Tianjin Key Laboratory of Membrane Science and Desalination Technology, Tianjin 300072. People's Republic \\ of China
}

(Received: 18 March 2019; accepted: 23 June 2019)

Casein peptides with calcium-chelating capacity were rapidly enriched by using a novel ceramic matrix (CM)-based $\mathrm{Ti}^{4+}$-IMAC adsorbent. The ability of calcium-chelating peptides (CCPs) to bind calcium and the physical properties of complexes formed between CCPs and calcium were investigated. Results demonstrated that the amount of calcium bound depended on the degree of hydrolysis (DH) of casein hydrolysates. The highest calcium binding capacity $\left(683 \mathrm{mg} \mathrm{g}^{-1}\right)$ occurred when bovine casein was hydrolysed by pancreatin at a $\mathrm{DH}$ of $0.14 \%$, meanwhile, the calcium content of CCPs-Ca complex exhibited the maximum level $\left(134.96 \mathrm{mg} \mathrm{g}^{-1}\right)$. In addition, CCPs showed a higher radical scavenging capacity $\left(50 \mu \mathrm{g} \mathrm{ml}^{-1} ; 99 \%\right.$ inhibition, or an equivalent activity of $9.91 \times 10^{-3} \mathrm{M}$ Trolox $)$ compared to casein digest. Moreover, Fourier-transform infrared spectroscopy and fluorescence spectroscopy were used to explore the interaction between CPPs and calcium, and the results demonstrated that phosphoserine residues as well as $\mathrm{COO}^{-}$groups of CCPs were involved in the formation of CCPs-Ca complex.

Keywords: casein hydrolysate, calcium chelate, enrichment, antioxidation

Calcium modulates several physiologic functions and its deficiency results in many diseases. As reported, calcium supplementation could increase physical activity in children, adolescents, and women. However, ionized calcium is prone to form calcium phosphate deposition in the intestinal environment, resulting in a low absorption. Calcium-chelating peptides (CCPs) have been proved to be effective in promoting $\mathrm{Ca}$ absorption, because peptide-Ca chelate could remain soluble, prevent dissociation and loss of $\mathrm{Ca}$ through the digestive system due to the bond between $\mathrm{Ca}$ and peptides.

Casein, accounting for approximately $80 \%$ of the total proteins in mammalian milk, is a family of four phosphorylated proteins, namely $\alpha_{\mathrm{s1}}{ }^{-}, \alpha_{\mathrm{s2}}-, \beta-$, and $\kappa$-casein. Currently, casein is widely used as a protein source in foods. A variety of reports show that casein peptides are both water soluble and have high nutritional values. Casein peptides are better absorbed than mixtures of free amino acids. Additionally, casein peptides, released either during food processing (by enzymatic hydrolysis or fermentation) or during gastrointestinal digestion, can be used as chelating agents with divalent metal ions (Liu et al., 2018), and also exhibit

\footnotetext{
* To whom correspondence should be addressed.

Phone: +86 22 2740.7599; fax: +86 22 2740.7599; e-mail: qiwei@tju.edu.cn
} 
several physiological activities, such as antioxidant, angiotensin-converting enzyme (ACE)inhibitory properties, antibacterial activity, partial cytoprotection (WANG et al., 2016), and so on. Thus, there is a great interest in developing casein peptides as nutraceutical for the formulation of functional foods.

Considering that ceramic matrix $(\mathrm{CM})$ is a favourable carrier of immobilized enzyme with the properties of biocompatibility and abrasive resistance (Wu et al., 2014) and the high specificity of $\mathrm{Ti}^{4+}$ to capture casein phosphopeptides (ZHOU et al., 2013), a novel CM-based $\mathrm{Ti}^{4+}$-immobilized metal ion affinity chromatography (IMAC) adsorbent was prepared and used for rapid enrichment of CCPs from casein hydrolysates in the present work. CM was easily prepared and mainly composed of some readily available metallic elements, such as calcium, silicon, aluminium, and magnesium, followed by modification with immobilized $\mathrm{Ti}^{4+}$. CCPs were enriched rapidly from casein digests, and the calcium binding ability, the radical scavenging activity of CCPs, as well as the calcium content of CCPs-Ca complex were determined. FTIR and fluorescence spectroscopy were employed to reveal the interaction between CCPs and Ca.

\section{Materials and methods}

\subsection{Materials and chemicals}

Bovine casein (Product Code C7078) of technical grade and porcine pancreatin (P7545) were purchased from Sigma Co. (USA). Acetonitrile (ACN) and trifluoroacetic acid (TFA) of HPLC grade were purchased from Merck (Darmstadt, Germany) and Dikma Co. (Beijing, China), respectively. Iminodiacetic acid (IDA) and 3-glycidoxypropyltrimethoxysilane (GLYMO) was purchased from Aladdin Chemical Reagent Co. Ltd. (Shanghai, China). Ultrapure water was obtained from an ELGA water purification unit (ELGA Ltd., Bucks, UK). All other reagents and solvents were of analytical grade and obtained from commercial source.

\subsection{Preparation of casein digest}

Bovine casein was digested as previously described (Su et al., 2007). Briefly, the bovine casein $\left(10 \mathrm{mg} \mathrm{ml}^{-1}\right)$ was hydrolyzed with pancreatin at an enzyme-to-protein ratio of 1/100 $(\mathrm{w} / \mathrm{w})$ in a batch reactor at $37^{\circ} \mathrm{C}$, and the $\mathrm{pH}$ was maintained at $8.0 \pm 0.1$ by adding $0.1 \mathrm{M}$ $\mathrm{NaOH}$ via potentiometric titration (Titro Line easy, Schott GmbH, Germany). During the reaction, aliquots of the hydrolysate were taken out at $10 \mathrm{~min}, 6 \mathrm{~h}, 12 \mathrm{~h}$, and $24 \mathrm{~h}$. Each aliquot was boiled at $100{ }^{\circ} \mathrm{C}$ for $10 \mathrm{~min}$ to stop the hydrolysis, and then lyophilized (FreeZone, LABCONCO, USA) after concentration in an R-2000 rotary evaporator (Shensheng Technology Co., Ltd., Shanghai).

\subsection{Determination of the degree of hydrolysis}

The degree of hydrolysis (DH), defined as the percentage of cleaved peptide bonds, was estimated from the amount of base added to keep the $\mathrm{pH}$ constant during hydrolysis (Navarrete-Del-Toro \& García-CARreño, 2002): 


$$
\mathrm{DH}(\%)=\frac{B N_{\mathrm{b}}}{\alpha M_{\mathrm{p}} h_{\mathrm{tot}}} \times 100
$$

where $B$ is the volume (millilitres) of base used to maintain the $\mathrm{pH} ; N_{\mathrm{b}}$ is the normality of the base; $1 / \alpha$ is the average degree of dissociation of $\alpha-\mathrm{NH}_{2}$ related to the $p K$ of the $\mathrm{NH}_{2}$ groups at particular $\mathrm{pH}$ and temperature; and $M_{\mathrm{p}}$ (grams) is the mass of protein in the reaction mixture, $h_{\text {tot }}(\mathrm{meq} / \mathrm{g})$ is the sum of millimoles of invidual amino acids per gram of protein associated with the source of protein used in the experiment. The total number of peptide bonds in the bovine casein protein substrate was assumed to be $8.2 \mathrm{meqv} / \mathrm{g}$ (NAVARRETE-DELTORO \& GARCÍA-CARREÑO, 2002).

\subsection{Enrichment of CPPs via Ti ${ }^{4+}-I D A-G L Y M O @ C M$}

CM was prepared according to the procedure developed by Wu and co-workers (2013), then $\mathrm{Ti}^{4+}$-IDA-GLYMO@CM was synthesized according to the method described by ZHOU and co-workers (2013) as shown in Figure 1. The enrichment protocol for CCPs is shown in Figure 2A and described as follows: the synthesized Ti ${ }^{4+}$-IDA-GLYMO@CM (100 mg)was mixed with $1 \mathrm{ml}$ of casein digest solution (dissolved in the loading buffer of $80 \%(\mathrm{v} / \mathrm{v}) \mathrm{ACN}$ and $6 \%(\mathrm{v} / \mathrm{v})$ TFA, $\left.10 \mathrm{mg} \mathrm{ml}^{-1}\right)$, and the mixture was stirred at $37^{\circ} \mathrm{C}$ for $1 \mathrm{~h}$; the $\mathrm{Ti}^{4+}$-IDAGLYMO@CM was isolated from the mixture by centrifugation (9000 r.p.m., $10 \mathrm{~min}$ ), and then the peptide-loaded Ti ${ }^{4+}$-IDA-GLYMO@CM was washed with solution $1[50 \%(\mathrm{v} / \mathrm{v})$ ACN and $0.5 \%(\mathrm{v} / \mathrm{v})$ TFA containing $200 \mathrm{mM} \mathrm{NaCl}]$ and solution $2[50 \%(\mathrm{v} / \mathrm{v}) \mathrm{ACN}$ and $0.5 \%(\mathrm{v} / \mathrm{v}) \mathrm{TFA}]$ three times; subsequently, the trapped CCPs were eluted by solution $3[10 \%$ $\left.(\mathrm{v} / \mathrm{v}) \mathrm{NH}_{3} \cdot \mathrm{H}_{2} \mathrm{O}\right]$ and solution $4[80 \%(\mathrm{v} / \mathrm{v}) \mathrm{ACN}$ and $2 \%(\mathrm{v} / \mathrm{v}) \mathrm{TFA}]$ three times; finally the eluate was collected and then lyophilized after removing organic solvents via a rotary evaporation.
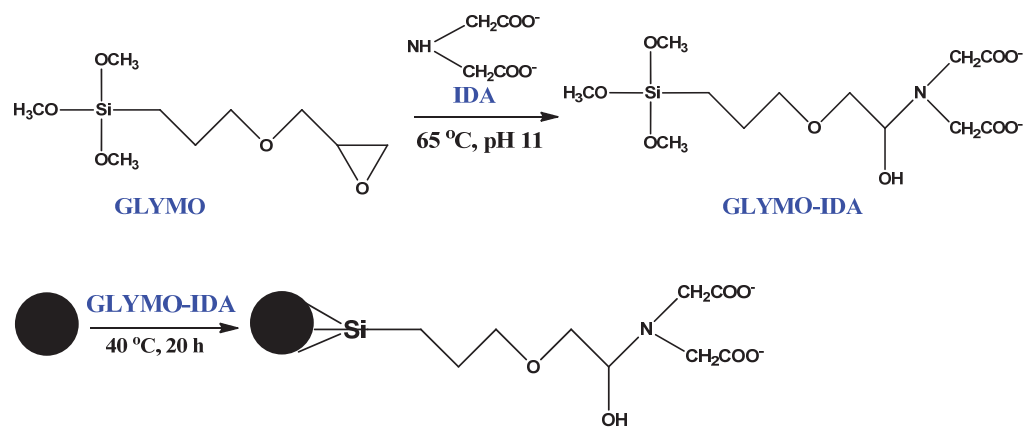

CM

CM@GLYMO-IDA

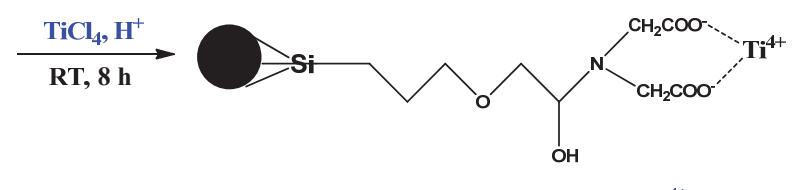

CM@GLYMO-IDA-Ti ${ }^{4+}$

Fig. 1. Schematic illustration of the preparation of $\mathrm{Ti}^{4+}$-IDA-GLYMO@CM 


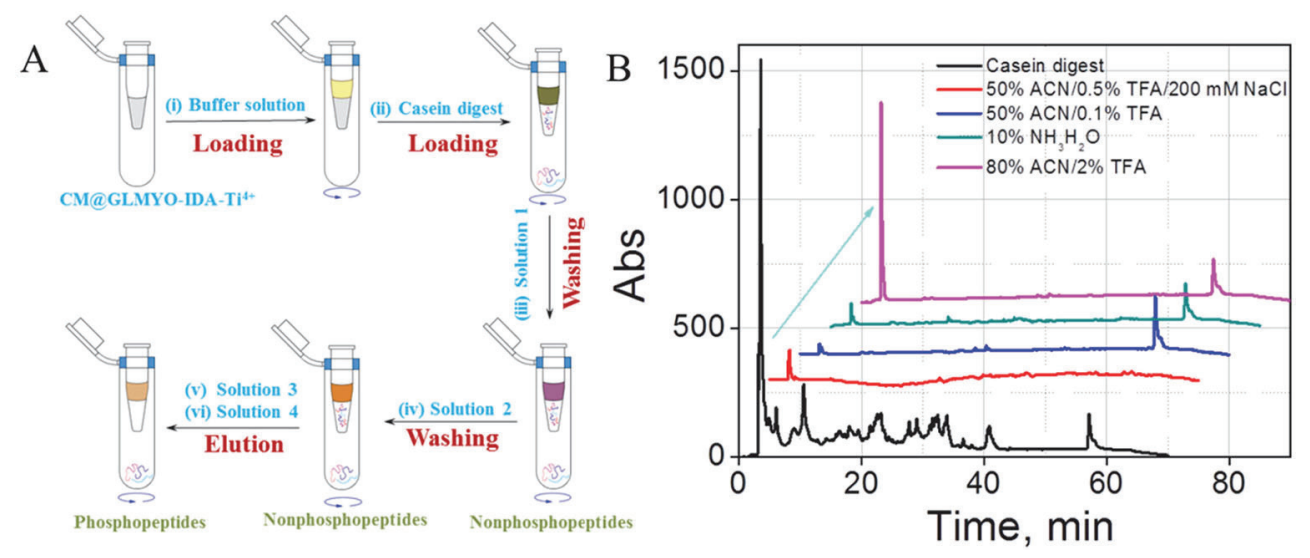

Fig. 2. (A) Flowchart indicating the enrichment of casein pancreatic hydrolysates by $\mathrm{Ti}^{4+}$-IDA-GLYMO@CM, (B) RP-HPLC chromatograms of casein digest $(24 \mathrm{~h})$ as well as samples eluted by solution $1,2,3$, and 4 , respectively

\subsection{Preparation of peptide-calcium complexes (CCPs-Ca)}

A 60-mg portion of each lyophilized hydrolysate was dissolved in $20 \mathrm{mM}$ Tris- $\mathrm{HCl}$ (pH 7.4) buffer solution at a concentration of $10 \mathrm{mg} \mathrm{ml}^{-1}$, followed by a 10 -min incubation at $37^{\circ} \mathrm{C}$ to ensure full dissolution. After adding of $3.75 \mathrm{ml}$ of $0.8 \mathrm{M} \mathrm{CaCl}_{2}$, the solution was maintained for $1 \mathrm{~h}$ at $37^{\circ} \mathrm{C}$. Then the mixture was placed in dialysis bags (MWCO 500, Spectrum, USA) and dialyzed in $400 \mathrm{ml}$ of $20 \mathrm{mM}$ Tris- $\mathrm{HCl}\left(\mathrm{pH} \mathrm{7.4)}\right.$ at $4{ }^{\circ} \mathrm{C}$ to remove free $\mathrm{Ca}^{2+}$, with the dialysate changed every $4 \mathrm{~h}$ over a period of $48 \mathrm{~h}$. Finally, the mixture solution was freezedried and the CCPs-Ca complex was prepared.

\subsection{Measuring the inhibition of the formation of insoluble calcium phosphate}

The $\mathrm{Ca}^{2+}$-binding abilities of different casein digest samples as well as CCPs were indirectly determined by measuring the inhibition of the formation of insoluble calcium phosphate according to the method reported previously (BERROCAL et al., 1989).

\subsection{Determination of calcium content}

Calcium binding ability was determined via titration with standard EDTA solution using calmagite as indicator according to the method described by LIU and co-workers (2013).

\subsection{Measurement of ABTS radical scavenging activity}

ABTS radical scavenging activities of the hydrolyzed samples and CCPs were determined by the spectrophotometric method previously described by RE and co-workers (1999). Results were expressed as $10^{-3} \mathrm{mM}$ Trolox.

\subsection{Reversed-phase high-performance liquid chromatography}

The casein digest as well as samples eluted by solutions 1, 2, 3, and 4, respectively (Section 1.5), were analysed by reversed-phase high-performance liquid chromatography (RP-HPLC) according to the method described in our previous report (Wu et al., 2013). 


\subsection{Scanning electron microscopy}

The surface morphology analyses of $\mathrm{Ti}^{4+}$-IDA-GLMYO@CM and CM were conducted on a scanning electron microscope (SEM) (FEI-Apreo). Each sample was previously fixed on a brass stub using double-sided adhesive carbon tape, which became electrically conductive by being coated with a thin layer of gold upon the surface for $30 \mathrm{~s}$ at $30 \mathrm{~W}$ in vacuum, and then was examined at an excitation voltage of $15 \mathrm{kV}$.

\subsection{Fourier-transform infrared spectroscopy}

FTIR spectra were obtained in the transmission mode within the scanning range from 400 to $4000 \mathrm{~cm}^{-1}$ using a Magna-IR560 instrument (Nicolet, USA). All operations were carried out in a dry atmosphere at room temperature $\left(25 \pm 1{ }^{\circ} \mathrm{C}\right)$, and the results were recorded in transmittance units.

\subsection{Fluorescence spectroscopy}

Fluorescence spectra were recorded on a spectrofluorimeter (Cary Eclipse, Agilent Technology Inc.) at $37^{\circ} \mathrm{C}$. The concentration of CCPs $(10 \mathrm{~min}, 6 \mathrm{~h}, 12 \mathrm{~h}$, and $24 \mathrm{~h}$, respectively) was $4 \mathrm{mg} \mathrm{ml}^{-1}$ (20 mM Tris-HCl, $\left.\mathrm{pH} 7.4\right)$. A certain amount of $\mathrm{CaCl}_{2}$ solution was added to the experimental groups to obtain a final concentration of $\mathrm{Ca}^{2+}\left(0.160 \mathrm{~mol} \mathrm{l}^{-1}\right)$. As for the control groups, the equal volume of $\mathrm{dH}_{2} \mathrm{O}$ was used. All groups were incubated for $30 \mathrm{~min}$ at $37^{\circ} \mathrm{C}$ before measurement. An excitation wavelength of $220 \mathrm{~nm}$ was chosen, and emission spectra were recorded within the range of 230 to $420 \mathrm{~nm}$.

\section{Results and discussion}

\subsection{Preparation and characterization of $T i^{4+}-I D A-G L M Y O @ C M$}

Due to biocompatibility and abrasive resistance of CM, CM-based $\mathrm{Ti}^{4+}$-IMAC adsorbent was prepared (Fig. 1) and used to enrich CCPs. The images of surface structure of $\mathrm{Ti}^{4+}$-IDAGLMYO@CM and CM were visualized by SEM (Fig. 3). It is assumed that the superior macroporous structure would be beneficial for capturing CCPs efficiently.

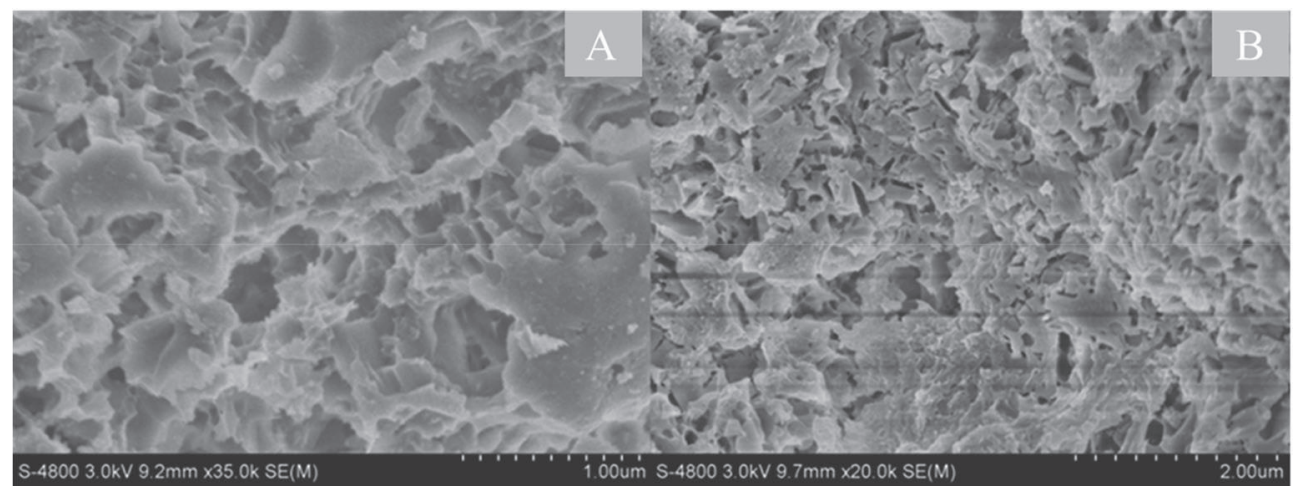

Fig. 3. SEM images of (A) CM and (B) $\mathrm{Ti}^{4+}$-IDA-GLYMO@CM 


\subsection{Enrichment and evaluation of $C C P S$}

Peptides with calcium-chelating capacity in the casein digest were enriched via $\mathrm{Ti}^{4+}$-IDAGLYMO@CM according to the procedure shown in Figure 2A. As shown in Figure 2B, the RP-HPLC chromatogram of CCPs (eluted by $80 \%$ ACN/2\% TFA) was much cleaner than that of casein digest, indicating that peptides with the ability of chelating metals were indeed purified.

The $\mathrm{Ca}^{2+}$-binding abilities of different casein digest samples as well as CCPs were indirectly determined by measuring the inhibition of the formation of insoluble calcium phosphate. The results presented in Figure 4 show that the consumption of $\mathrm{NaOH}$ solution significantly decreased when CCPs were added, demonstrating that the formation of insoluble calcium phosphate could be inhibited by CCPs. It is worth noting that 10-min CCPs showed higher calcium-binding ability $\left[683 \mathrm{mg}\left(\mathrm{Ca}^{2+}\right) / \mathrm{g}(\mathrm{CCPs})\right]$. Similarly, the maximum value of the contents of calcium in CCPs-Ca complexes occurred in the case of 10 min-CCPs (Fig. $5 \mathrm{~A}$ ). These results might be explained by the fact that most of CCPs with the cluster sequence -SerP-SerP-SerP-Glu-Glu- were released within $10 \mathrm{~min}$ but hydrolyzed with the increase of DH (Su et al., 2007). Therefore, phosphoserine residues seem to play a pivotal role in calcium chelation.
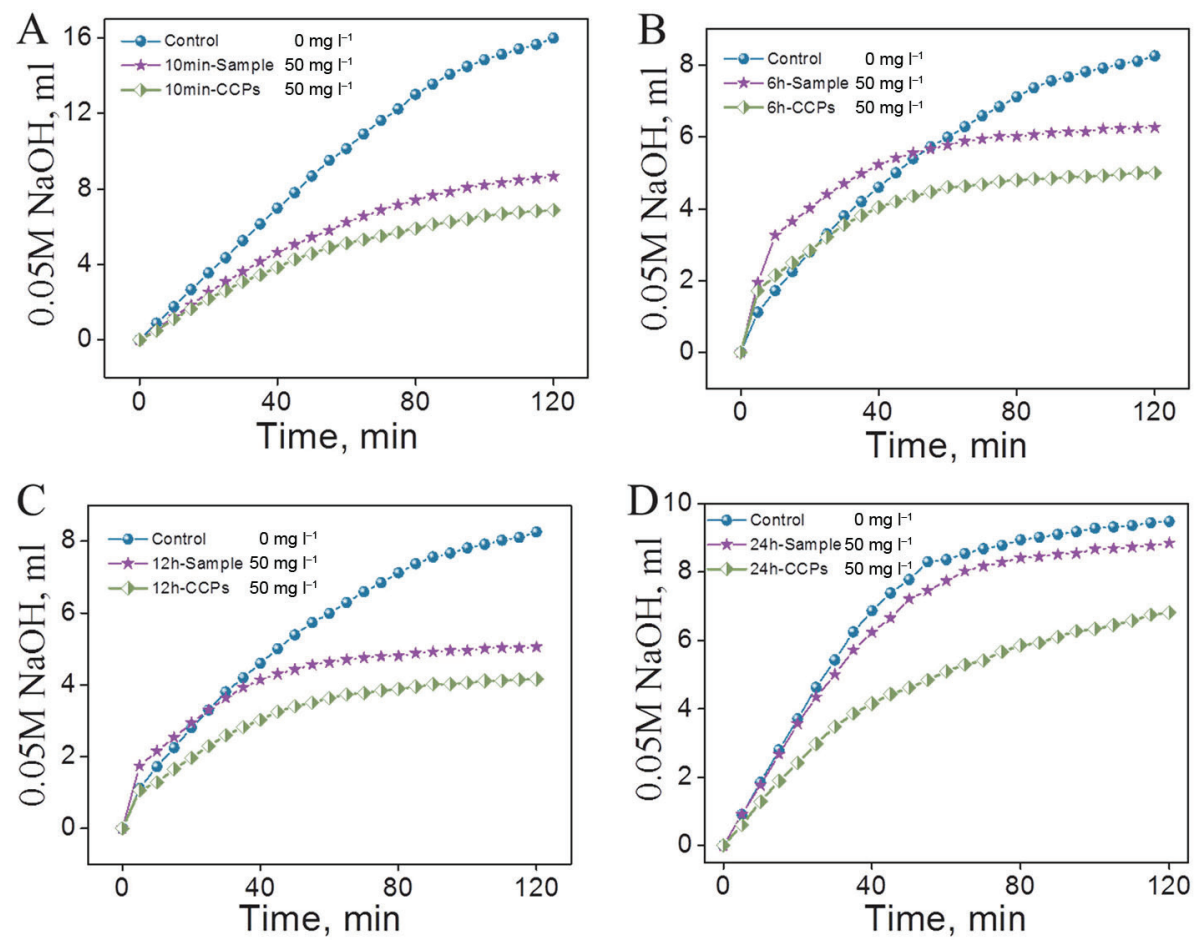

Fig. 4. Performance curves for the ability to inhibit the formation of insoluble calcium phosphate of casein digest samples as well as CCPs with different hydrolysis times (A) $10 \mathrm{~min}$, (B) $6 \mathrm{~h}$, (C) $12 \mathrm{~h}$, (D) $24 \mathrm{~h}$. Conditions: temperature $37^{\circ} \mathrm{C}$, $\mathrm{pH} 7.2$, and the concentration of casein digest samples or CCPs $50 \mathrm{mg} \mathrm{ml}^{-1}$ 


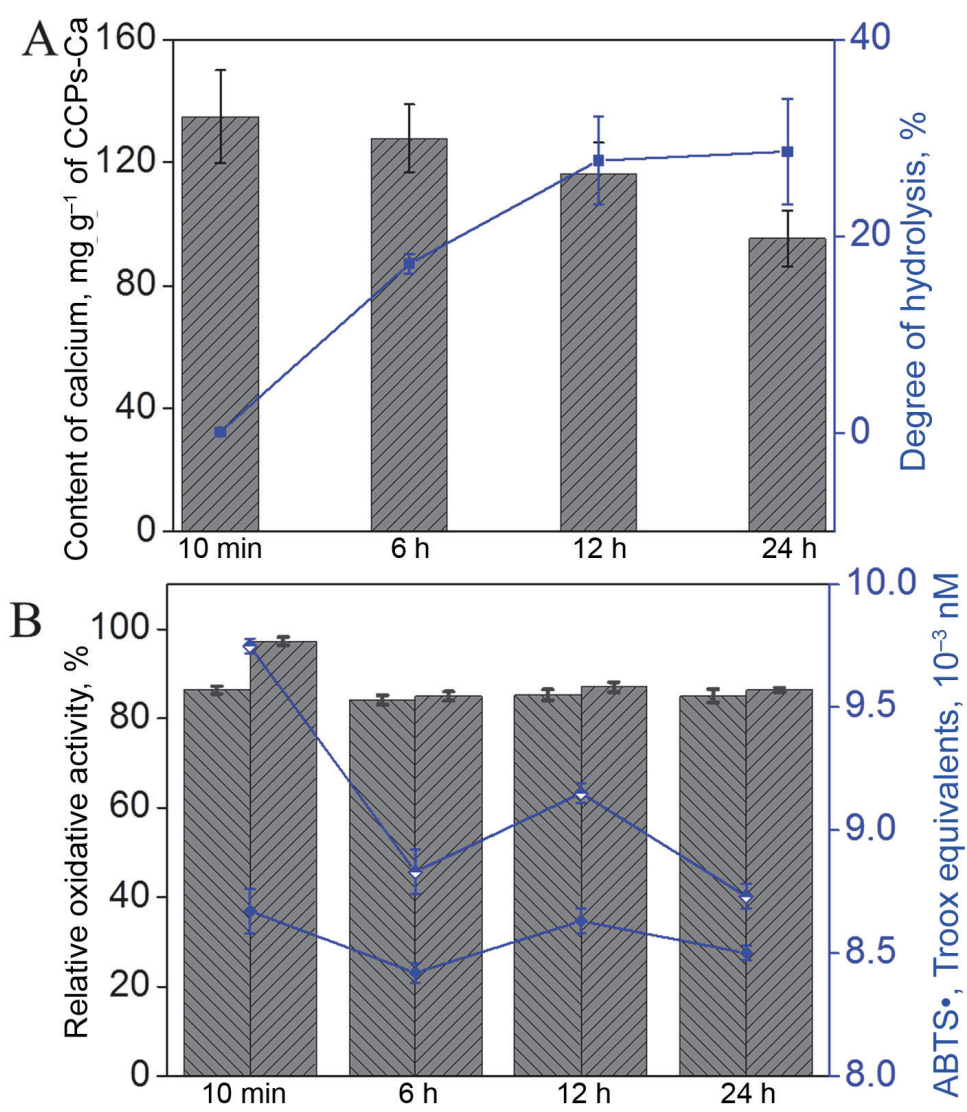

Fig. 5. (A) Degree of hydrolysis of casein hydrolysates with different reaction times and contents of calcium in CCPs-Ca complexes, (B) ABTS radical activity (inhibitory, \%; Trolox equivalent, $10^{-3} \mathrm{mM}$ ) of casein digest $\left(250 \mu \mathrm{g} \mathrm{ml}^{-1}\right)$ and CCPs $\left(50 \mu \mathrm{g} \mathrm{ml}^{-1}\right)$ of different hydrolysis times $(10 \mathrm{~min}, 6 \mathrm{~h}, 12 \mathrm{~h}$, and $24 \mathrm{~h})$

A: $\mathbb{Z}$ : Content of calcium; B: Casein digest; $\mathbb{Z}$ : CCPs; $\multimap$ : Casein digest; $\multimap$ : CCPs

Additionally, the scavenging capacities of CCPs and the casein digest were estimated by the ABTS $\cdot{ }^{+}$decolourization assay and results, expressed as $\%$ inhibition of ABTS $\cdot{ }^{+}$as well as $10^{-3} \mathrm{M}$ Trolox, are displayed in Figure 5B. Obviously, there was no significant difference among free radical scavenging activity of casein digest $\left(250 \mu \mathrm{g} \mathrm{ml}^{-1} ; 86.3 \%, 84.1 \%, 85.2 \%\right.$, and $85 \%$ for $10 \mathrm{~min}, 6 \mathrm{~h}, 12 \mathrm{~h}$, and $24 \mathrm{~h}$-casein digests, respectively). However, a maximum capacity ( $99 \%$ inhibition or an equivalent activity of $9.91 \times 10^{-3} \mathrm{M}$ Trolox) was obtained for $10 \mathrm{~min}-\mathrm{CCPs}$ at $50 \mu \mathrm{g} \mathrm{ml}^{-1}$, although those of other CCPs were similar $(90.1 \%, 91.2 \%$, and $86.8 \%$ for 6 h, 12 h, and 24 h, respectively). Furthermore, at the hydrolysis time of $6 \mathrm{~h}, 12 \mathrm{~h}$, as well as $24 \mathrm{~h}$, the enriched CCPs at a lower concentration $\left(50 \mu \mathrm{g} \mathrm{ml}^{-1}\right)$ provided similar scavenging activity as the casein digest at $250 \mu \mathrm{g} \mathrm{ml}^{-1}$. All these results demonstrated that the CCPs enriched through $\mathrm{Ti}^{4+}$-IDA-GLYMO@CM presented more effective primary antioxidant potential than casein digest.

Several amino acids have been proved to exhibit antioxidant activity. The radical scavenging activities of His and Tyr were thought to be due to the hydrogen-donating ability 
of the imidazole group (CHAN et al., 1994) and the phenolic hydroxyl group (CHEN et al., 1996), respectively. Additionally, studies have indicated that the antioxidative activity of peptides depend on their constituent amino acids (CHEN et al., 1996). As for CCPs, the potential functional domain (-SerP-SerP-SerP-Glu-Glu-) acting not only as metal sequestering, but also hydrogen/electron donation, was considered to provide more pronounced radical scavenging activity (KITTS, 2005).

\subsection{Fourier-transform infrared spectroscopy}

The Fourier-transform infrared spectroscopy (FTIR) could provide information about amino acid residues in $\mathrm{Ca}^{2+}$-binding peptides (NARA \& TANOKURA, 2008; NARA et al., 2013). FTIR spectra of CPPs and Ca-binding CCPs are shown in Figure 6. The results indicate that CCPsCa complexes have formed, since variations of FTIR spectra are obvious after addition of calcium. In the spectra of CCPs-Ca, red shifts in the region $1700-1600 \mathrm{~cm}^{-1}$, assigned to the $\mathrm{C}=\mathrm{O}$ stretch (mixed with the $\mathrm{N}-\mathrm{H}$ bend and the $\mathrm{C}-\mathrm{N}$ stretch), indicated the involvement of the carboxylic group in complex formation. Significant changes to the band around $1400 \mathrm{~cm}^{-1}$ assigned to $\mathrm{COO}^{-}$(NARA \& TANOKURA, 2008) reflected the form of Ca-bound peptides. This suggested that the 'free' $\mathrm{COO}^{-}$groups of some amino acid residues, such as Asp and Glu, were also involved in Ca-peptide complex formation. Moreover, the absorption band near $1350-1100 \mathrm{~cm}^{-1}$ attributed to the $\mathrm{P}=\mathrm{O}$ stretch (TRINDADE et al., 1997) presented noticeable changes, suggesting that it was probably the calcium bound to CCPs through interactions with phosphoserine residues.
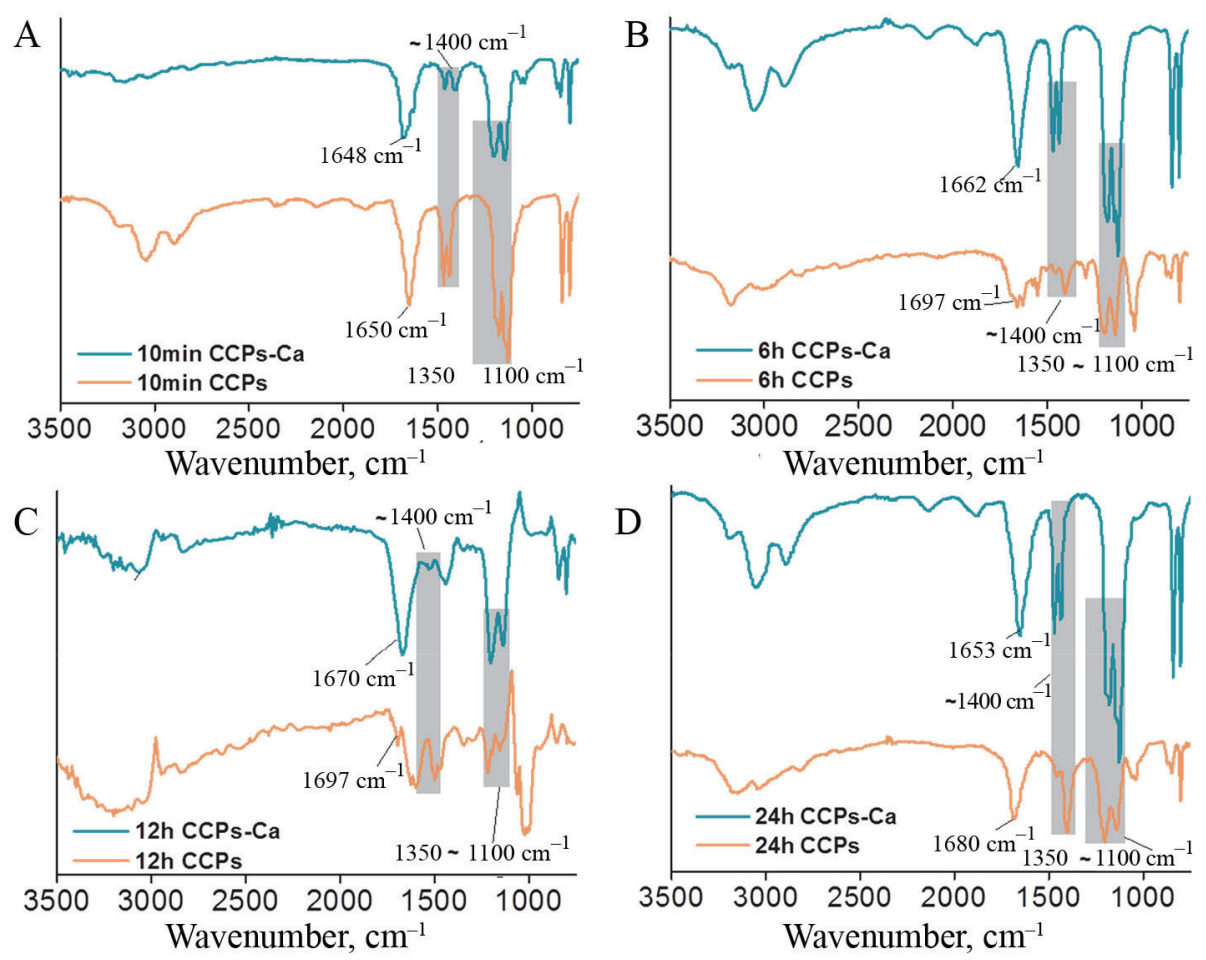

Fig. 6. FTIR spectra of CCPs and CCPs-Ca complexes at different hydrolysis times (A) $10 \mathrm{~min}$, (B) $6 \mathrm{~h}$, (C) $12 \mathrm{~h}$, (D) $24 \mathrm{~h}$ 


\subsection{Fluorescence spectroscopy}

The fluorescence spectroscopy has provided valuable insights into the metal-binding properties of proteins (KIRBERGER et al., 2013; TOKUNAGAO et al., 2013), since there are three aromatic amino-acid residues (phenylalanine, Phe; tyrosine, Tyr; tryptophan, Trp) that contribute to their ultraviolet fluorescence.
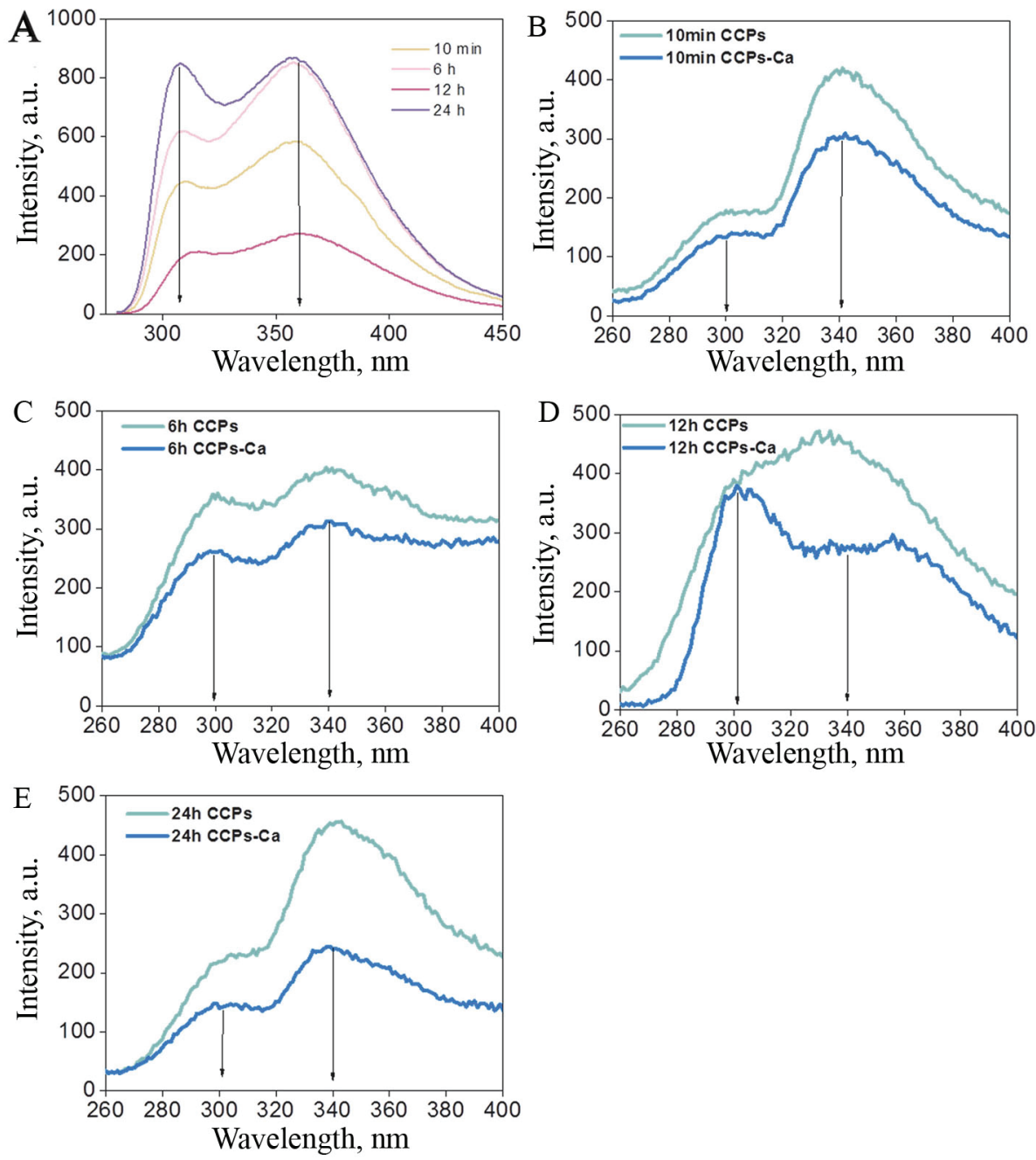

Fig. 7. (A) Fluorescence spectra of casein digest at various time points, conditions: concentration of samples, 5 $\mathrm{mg} \mathrm{ml}^{-1}$ (20 mM Tris-HCl, pH 7.4); excitation wavelength, $270 \mathrm{~nm}$; emission spectra, 280-540 nm; temperature, $37^{\circ} \mathrm{C}$; (B-E) CCPs with or without calcium at different hydrolysis times (10 min, $6 \mathrm{~h}, 12 \mathrm{~h}$, and $\left.24 \mathrm{~h}\right)$; Conditions:

$\mathrm{C}_{\mathrm{CCPs}}=4 \mathrm{mg} \mathrm{ml}^{-1} ; \mathrm{C}_{\mathrm{Ca}}{ }^{2+}=0.160 \mathrm{~mol} \mathrm{l}^{-1} ; \lambda \mathrm{ex}=220 \mathrm{~nm}$; emission spectra, $230-420 \mathrm{~nm}$; temperature, $37^{\circ} \mathrm{C}$

The emissions of Phe, Tyr, and Trp in water occur near $280 \mathrm{~nm}, 300 \mathrm{~nm}$, and $350 \mathrm{~nm}$, respectively. As shown in spectra of casein digest (Fig. 7A) and CPPs with or without calcium (Fig. 7B-E), Tyr and Trp emissions were observable, except that of Phe, which would be the 
result of energy transfer (LAKOWICZ \& MASTERS, 2008). Compared with the spectra of casein digest (Fig. 7A), blue-shifts happened to both Tyr and Trp emission in the spectra of CCPs (Fig. 7B-E). This phenomenon could be expected from the different degrees of solvent exposure of Tyr and Trp residues (LAKOWICZ \& MASTERs, 2008), and again proved the fact that CCPs could be purified via Ti ${ }^{4+}$-IDA-GLYMO@CM. Additionally, upon addition of calcium to CCPs, there was a decrease in intensity but no shifts of their Tyr and Trp emissions, showing that calcium-binding resulted in the quenching due to changes in the microenviroment around these two amino acid residues. Meanwhile, more significant change was observed in fluorescence intensity of Trp than that of Tyr, which might be due to the high sensitivity and the large effect of the local environment on molecular emission. Consequently, all above results proved the existence of interaction between calcium and CCPs.

\section{Conclusions}

In conclusion, CCPs with high calcium-chelating ability and radical scavenging capacity were successfully and rapidly enriched by $\mathrm{CM}$ based-Ti ${ }^{4+}$-IMAC adsorbent. The present work has provided an alternative material for purifying not only CCPs but also proteins or even other macromolecules.

This work was supported by the Natural Science Foundation of China (Nos. 21476165, 21621004), the 863 Program of China (No. 2013AA102204), the Ministry of Science and Technology of China (No. 2012YQ090194), the Beiyang Young Scholar of Tianjin University (2012), and the Program of Introducing Talents of Discipline to Universities of China (No. B06006).

\section{References}

Berrocal, R., Chanton, S., Juillerat, M., Pavillard, B., Scherz, J. \& Jost, R. (1989): Tryptic phosphopeptides from whole casein. II. Physicochemical properties related to the solubilization of calcium. J. Dairy. Res., $56(3), 335-341$.

Chan, K.M., Decker, E.A. \& Feustman, C. (1994): Endogenous skeletal muscle antioxidants. Crit. Rev. Food Sci., 34(4), 403-426.

Chen, H.M., Muramoto, K., Yamauchi, F. \& Nokihara, K. (1996): Antioxidant activity of designed peptides based on the antioxidative peptide isolated from digests of a soybean protein. J. Agr. Food Chem., 44, 2619-2623.

Kirberger, M., Wong, H.C., Jiang, J. \& Yang, J.J. (2013): Metal toxicity and opportunistic binding of Pb2+ in proteins. J. Inorg. Biochem., 125, 40-49.

KitTs, D. (2005): Antioxidant properties of casein-phosphopeptides. Trends Food Sci. Tech., 16(12), 549-554.

Lakowicz, J.R. \& Masters, B.R. (2008): Principles of fluorescence spectroscopy. J. Biomed. Opt., $13(2), 9901$.

Liu, G., Sun, S., Guo, B., MiaO, B., Luo, Z., ... \& Tang, J. (2018): Bioactive peptide isolated from casein phosphopeptides promotes calcium uptake in vitro and in vivo. Food Funct., 9, 2251-2260.

LiU, F., WANG, L., WANG, R. \& CHEN, Z. (2013): Calcium-binding capacity of wheat germ protein hydrolysate and characterization of peptide-calcium complex. J. Agr. Food Chem., 61(31), 7537-7544.

NARA, M., MoriI, H. \& TANOKURA, M. (2013): Coordination to divalent cations by calcium-binding proteins studied by FTIR spectroscopy. Biochem. Biophys. Acta, 1828(10), 2319-2327.

NARA, M. \& TANOKURA, M. (2008): Infrared spectroscopic study of the metal-coordination structures of calciumbinding proteins. Biochem. Bioph. Res. Co., 369(1), 225-239.

Navarrete-del-Toro, M.A. \& García-Carreño, F.L. (2002): Unit B2.3. Determination of degree of hydrolysis and protein digestibility. Part B. Chapter B2.2.1. -in: Biochemical compositional analyses of proteins. Current protocols in food analytical chemistry. John Wiley \& Sons, Inc., Suppl. 4. 
Re, R., Pellegrini, N., Proteggente, A., Pannala, A., Yang, M. \& Rice, C. (1999): Antioxidant activity applying an improved ABTS radical cation decolorization assay. Free Radical Bio. Med., 26(9), 1231-1237.

Su, R., QI, W., He, Z., YuAN, S. \& Zhang, Y. (2007): Pancreatic hydrolysis of bovine casein: Identification and release kinetics of phosphopeptides. Food Chem., 104(1), 276-286.

Tokunagao, Y., Matsumoto, M., Tokunaga, M., Arakawa, T. \& Sugimoto, Y. (2013): Amyloid fibril formation in vitro from halophilic metal binding protein: Its high solubility and reversibility minimized formation of amorphous protein aggregations. Protein Sci., 22(11), 1582-1591.

Trindade, T., O’Brien, P. \& Zhang, X. (1997): Synthesis of CdS and CdSe nanocrystallites using a novel singlemolecule precursors approach. Chem. Mater., 9(2), 523-530.

WANG, B., XIE, N. \& LI, B. (2016): Charge properties of peptides derived from casein affect their bioavailability and cytoprotection against $\mathrm{H}_{2} \mathrm{O}_{2}$-induced oxidative stress. J. Dairy Sci., 99(4), 2468-2479

Wu, S., QI, W., LI, T., Lu, D., Su, R. \& HE, Z. (2013): Simultaneous production of multi-functional peptides by pancreatic hydrolysis of bovine casein in an enzymatic membrane reactor via combinational chromatography. Food Chem., 141(3), 2944-2951.

Wu, Z., QI, W., WANG, M., Su, R. \& He, Z. (2014): Lipase immobilized on novel ceramic supporter with Ni activation for efficient cinnamyl acetate synthesis. J. Mol. Catal. B-Enzym., 110, 32-38.

Zhou, H., Ye, M., Dong, J., Corradini, E., Cristobal, A., Heck, A.J., Zou, H. \& Mohammed, S. (2013): Robust phosphoproteome enrichment using monodisperse microsphere-based immobilized titanium (IV) ion affinity chromatography. Nat. Protoc., 8(3), 461-480. 